\title{
Development of security camera with privacy protection and, social experiment using the security camera with privacy protection
}

\author{
Sogo kato ${ }^{\mathrm{a},{ }^{*}}$, Akihiro Takita ${ }^{\mathrm{a}}$, Noriaki Yoshiura ${ }^{\mathrm{b}}$, Naoya Ohta ${ }^{\mathrm{a}}$, \\ Kouichi Maru ${ }^{\mathrm{c}}$, Hiroshi Ueda ${ }^{\mathrm{d}}$, Hideo Matsuda ${ }^{\mathrm{e}}$, Yusaku Fujii ${ }^{\mathrm{a}}$ \\ ${ }^{a}$ School of Science and Technology, Gunma University, Kiryu 376-8515, Japan \\ ${ }^{\mathrm{b}}$ Graduate School of Science and Engineering, Saitama University, Sakura, Saitama 338-8570, Japan \\ ${ }^{c}$ Department of Electronics and Information Engineering, Faculty of Engineering, Kagawa University, \\ Takamatsu 761-0396, Japan \\ ${ }^{\mathrm{d}}$ Academic Center for Computing and Media Studies, Kyoto University, \\ Yoshidanihonmatsucho, Sakyoku, Kyoto 606-8501, Japan \\ ${ }^{\mathrm{e}}$ Matsuda Syouji, Kiryu 376-0021, Japan \\ *Corresponding Author: t15804021@gunma-u.ac.jp
}

\begin{abstract}
We conducted a social experiment using the e-JIKEI Camera $^{(1)}$ to create a model case for a safe and secure school route. In addition, in order to know the opinion about the security cameras, a public opinion survey is performed in the social experiment. The e-JIKEI Camera is security camera that was developed in collaboration with the company for spreading "e-JIKEI Network"(2-4) which encourages communities to monitor their surroundings with high densely installed camera for preventing crimes. The e-JIKEI Camera has an important feature which is useful for operating under privacy protection concept. The e-JIKEI Camera has the potential to significantly contribute to realizing a safe and secure school route.
\end{abstract}

Keywords: Security camera, Privacy protection, Safety of school route.

\section{Introduction}

In recent years, the installation of the security camera to stores, downtowns and public facilities has progressed. And there are many cases that security camera has helped to identify and to arrest the criminals. However, there are some opinions yet that the effect of security camera is doubted. We think that these opinion bases on installed number or density of camera rather than functions of security camera. If product cost and installation cost of the security camera is reduced more, installed number and density of security camera are increased. Then, the effect of security camera will be no doubt. We have proposed "e-JIKEI Network" concept which encourages to communities to monitor their surroundings, not inside their homes, with inexpensive security cameras as shown in Fig.1. We have promoted to install security cameras in residential area by producing software which compose a security camera with cheap computer and cheap web cameras. Additionally, we provided security cameras which are low installation cost and easy to use. However, increase of security camera causes worry about invasion of privacy and danger of arrival of a regimented society. We thought that the problems related to invasion of privacy and arrival of a regimented society can be solved by dividing the owner and viewer of the camera by proper selection and management of the two. We developed a security camera named "e-JIKEI Camera" in order to realize our privacy protection concept.

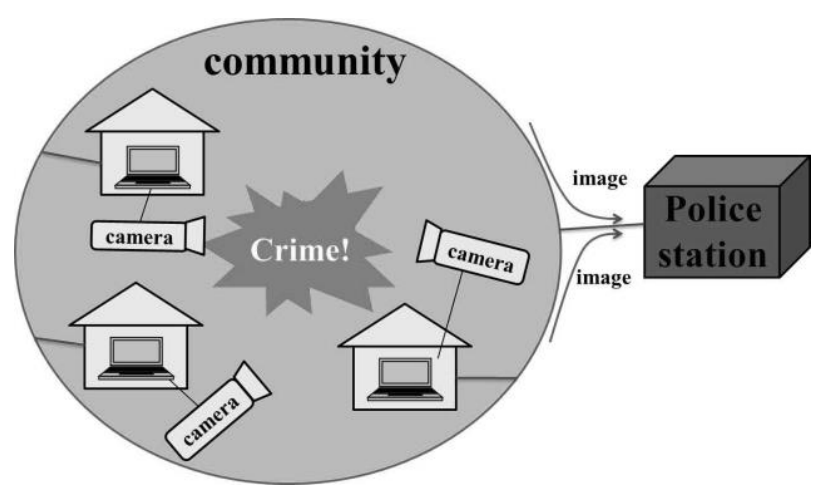

Fig. 1 Overview of the e-JIKEI Network. 


\section{Security camera with privacy protection}

\subsection{The e-JIKEI Camera (ejkc-ZB102c)}

We developed a new security camera called "e-JIKEI Camera" in collaboration with company for spreading "e-JIKEI Network". The e-JIKEI Camera has a function for realizing of the privacy protection. In this function, an image taken by the security camera is stored in the built in SD card with encryption. To view the encrypted image, a dedicated viewer software and passwords are required. In addition, there are two types in the passwords.

The first password called "Key A" is provided for the maintenance use. This password is owned mainly to maintenance company and neighborhood association which joins our social experiment. When the encrypted image is decrypted by the dedicated viewer software with the Key A, the image is displayed with a rough mosaic filter. Therefore, they cannot see a clear image. However, it is possible to perform the confirmation of the operation and the field of view. The second password called "Key B" is provided for investigation of crimes. This password is owned mainly by police and city office. Police and city office, can view a clear image by using both Key A and Key B. Therefore, they can utilize the clear image for investigation. Thus, it is possible to divide a person who can and who cannot view a clear image in this way. Therefore, the e-JIKEI Camera can protect privacy of general citizen.

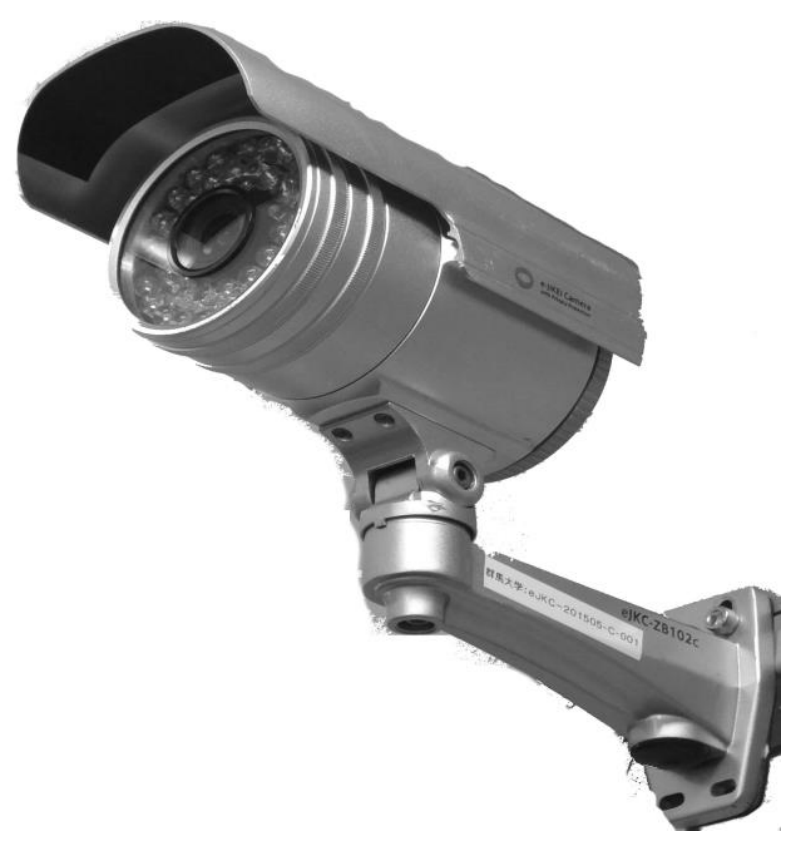

Fig. 2 e-JIKEI Camera(ejkc-ZB102c).
The e-JIKEI Camera includes the following features:

(A) Encrypted image will enable privacy protection by storing the internal SD card.

(B) The image is saved of about one week. And image is overwritten from the old image in the order.

(C) The e-JIKEI Camera can take images even at night.

(D) The e-JIKEI Camera can be operated by the power supply at the AC100V. And other wiring is unnecessary.

(E) The e-JIKEI Camera has waterproof function.

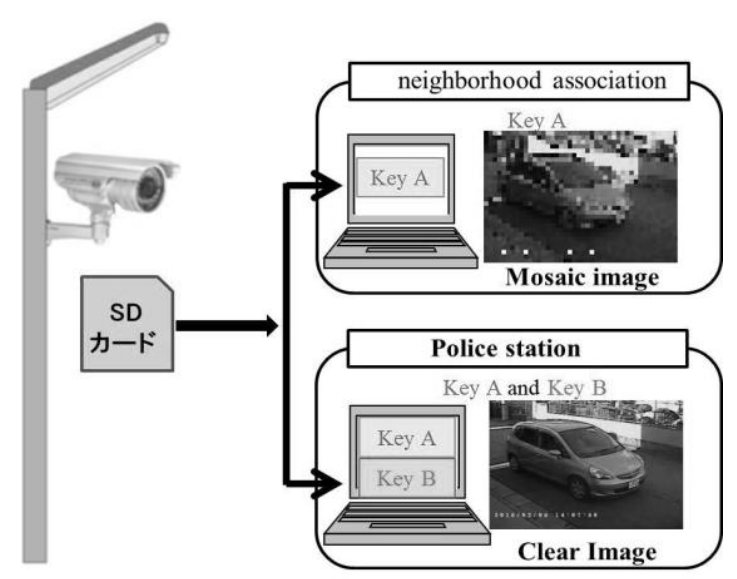

Fig. 3 Operation method of the e-JIEKI Camera.

\subsection{Social experiment}

A social experiment started using 8 units of the e-JIKEI Camera (ejkc-ZB102c) from January 28, 2015 in the Nishihoncho Ota city in Gunma prefecture. The e-JIKEI cameras are installed to monitor the school route, as shown in Fig.4-6. These e-JIKEI Camera have been installed a suitable place on monitoring without blind spot of the social experiment area. Fig.7 shows the locations and directions of the 8 units e-JIKEI Cameras.

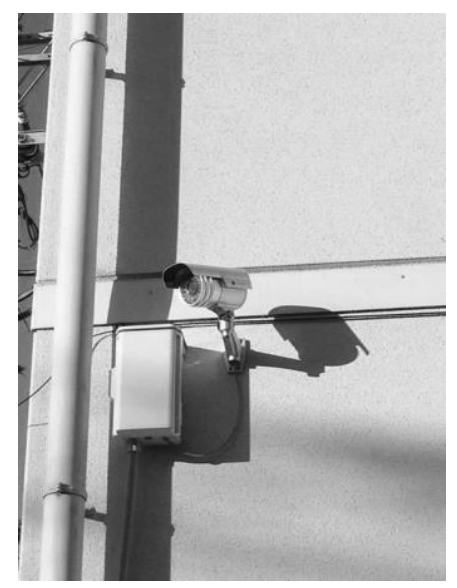

Fig. 4 Installation situation (1). 


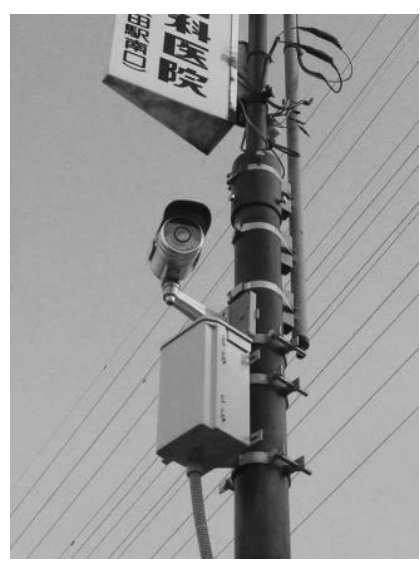

Fig. 5 Installation situation (2).

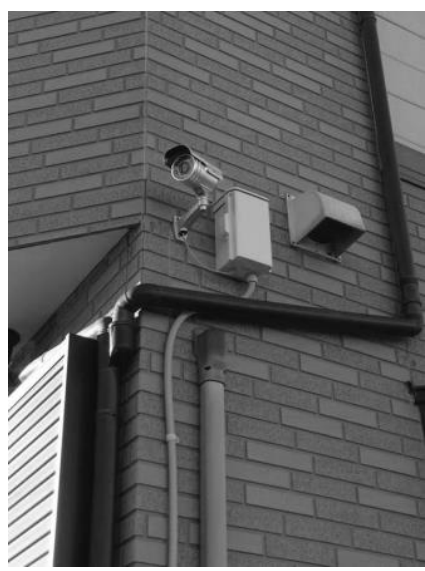

Fig. 6 Installation situation (3).

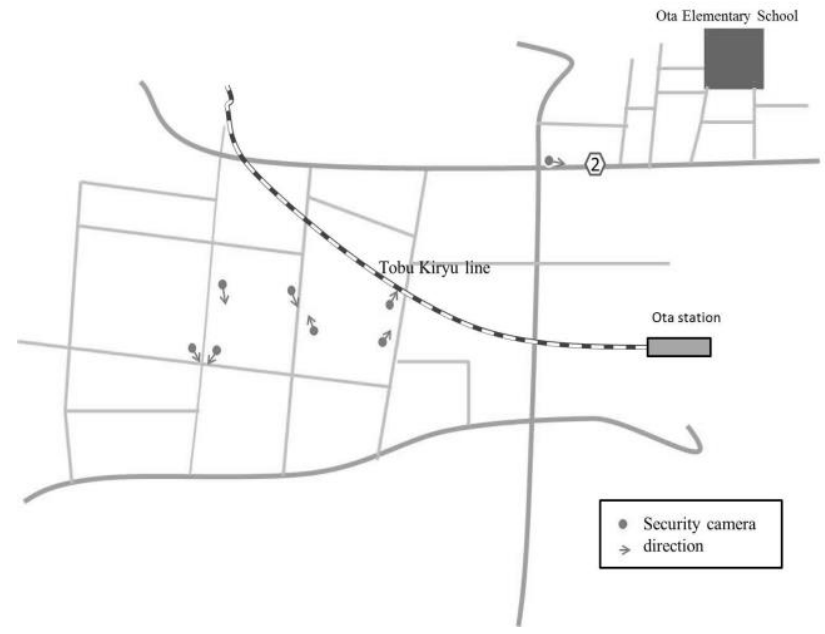

Fig. 7 Location of the e-JIKEI Camera.

The purpose of this social experiment is to create a model case of contribute to the safety and security improvement of the society and school route by monitoring by security cameras that have been installed at a high density a certain area of among the school route. In this social experiment using the e-JIKEI Camera, we have established the method of handling the Key A and B as follows in order to protect the privacy of general citizen.

(A) Chief of Community Safety Division in Ota police station sets and manages both password Key A, Key B.

(B) Nishihoncho neighborhood association and maintenance company manage only Key A which is announced from the police station.

(C) Our laboratory does not know any password.

We performed opinion surveys three times in this social experiment. The first survey was conducted on a social experiment information session at two month before the social experiment. The second survey was conducted at the beginning ceremony of the social experiment. The third survey was conducted after three days of social experiment because hear a lot of opinion than when for the second survey. The targets of the questionnaires were the residents of Nishihoncho, the location of the social experiment. In this questionnaire, we inquired about resident's opinions about the security camera whether security camera with privacy protection feature will be widely accepted in the community. Fig. 8 shows the result for the question about whether privacy protection feature is required in security camera. As a result, 96\% of people have answered Yes. Fig. 9 shows the result for the question about whether the e-JIKEI Camera will be widely acceptable to the community. As a result, $41 \%$ of the people answered "Extremely accepted", 54\% of people answered "Moderately accepted". Fig.10 shows the results of whether the residents want to participate with efforts to installation of the e-JIKEI Camera. As a result, $37 \%$ of people have answered "I want to participate" and $60 \%$ of people have answered "I want to participate conditionally".

Do you think that a function of privacy protection is necessary for a security camera?

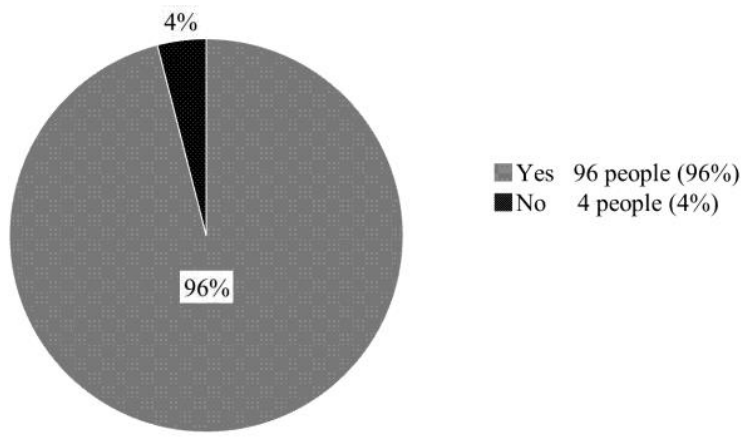

Fig. 8 Result of questionnaires (1). 
Do you want to participate with efforts to installation of the e-JIKEI Camera?

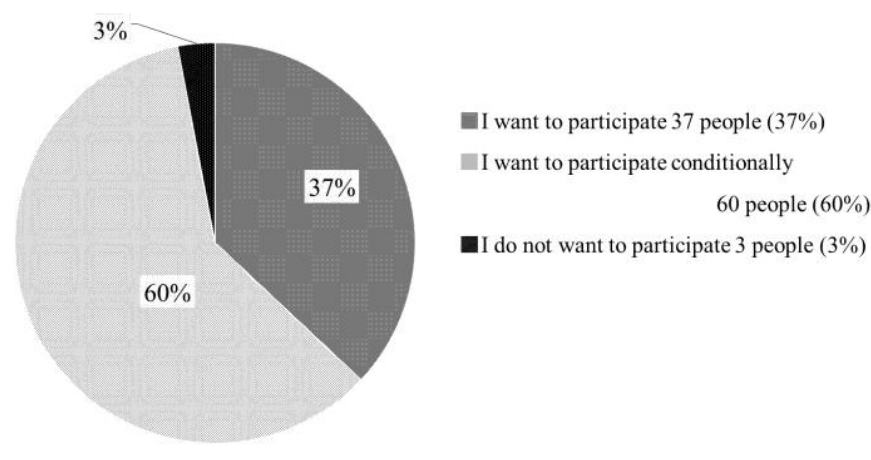

Fig. 9 Result of questionnaires (2).

Do you think that the e-JIKEI Camera will be accepted in the widely community?

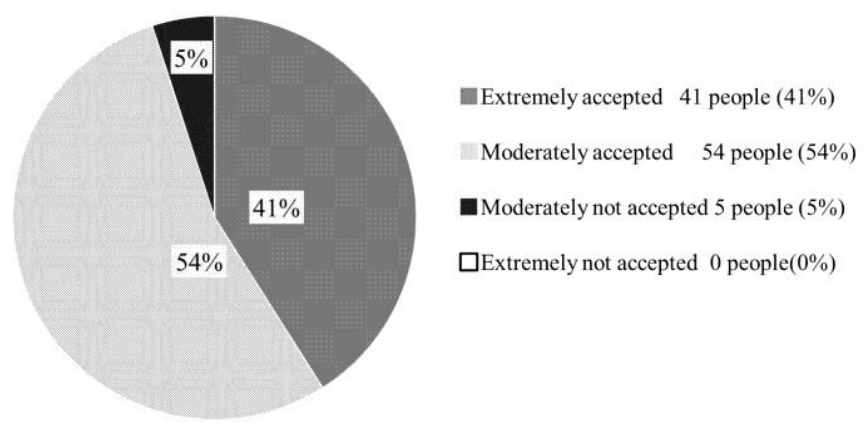

Fig. 10 Result of questionnaires (3).

\section{Discussion}

The social experiment using 8 units security cameras showed that high density and installed security camera can improve safety and security of the school route. The huge number of security cameras are possible to suppress a crime, to find the criminal quickly at the time of crimes and to realize a safe and secure school route. Thus, a school route will become more safe place for child, parents and residents. One of the most important barriers to the wide use of security cameras is an invasion of privacy. The result of the opinion survey indicates the necessity of installing the privacy protection function to the security cameras. In this social experiment, we have used a security camera with a function of privacy protection. We have established the guideline in order to protect the privacy of general citizen. Thus, the problem of invasion of privacy was solved by using the e-JIKEI Camera. As a result of opinion surveys, our security camera "e-JIKEI Camera" will be accepted widely into communities. If our effort is accepted by every community, then a considerable number of security cameras will be introduced in communities throughout the country and the world. Then, every school route will be monitored by numerous cameras to realize safe and secure route. If a crime occurs, the police will be able to arrest the suspect immediately by using the image of the many security cameras.

\section{Conclusions}

We conducted a social experiment using the e-JIKEI Camera to create a model case for a safe and secure school route. In addition, in order to know the opinion about the inhabitants of the security cameras, a public opinion survey was performed on the social experiment. The e-JIKEI Camera has a function of privacy protection. The cameras were operated properly, for a balance of monitoring and privacy protection in the social experiment. We believe that this e-JIKEI Camera can contribute to the realization of a safe and secure community.

\section{Acknowledgment}

This study was supported in part by the Grant-in-Aid for Scientific Research (B) $15 \mathrm{H} 02887$ (KAKENHI 15H02887).

\section{References}

(1) Yusaku Fujii, Koichi Maru, Kojiro Kobayashi, Noriaki Yoshiura, Naoya Ohata, Hiroshi Ueda, and Preecha Yupapin : “e-JIKEI Network using e-JIKEI Cameras: Community security using considerable number of cheap stand-alone cameras", Safety Science, vol.48,pp.912-925,2010

(2) NPO, The e-JIKEI Network Promotion Institute. $<$ http://www.e-jikei.org/>

(3) Yusaku Fujii, Noriaki Yoshiura, and Naoya Ohta : "Creating a worldwide community security structure using individually maintained home computers: The e-JIKEI Network Project", Social Science Computer Review, Vol.23, No.2, pp. 250-258, 2005

(4) Yusaku Fujii, Koichi Maru, Noriaki Yoshiura, Naoya Ohta, Hiroshi Ueda, and Youichi Sugita : "New concept regarding management of security cameras", Journal of Community Informatics, vol.4,2008 